\title{
Effect of Understress on Fretting Fatigue Crack Initiation of Press-Fitted Axle*
}

\author{
Masanobu KUBBOTA**, Sotaro NIHO $^{* * *}$, \\ Chu SAKAE** and Yoshiyuki KONDO**
}

\begin{abstract}
Axles are one of the most important components in railway vehicles with regard to safety, since a fail-safe design is not available. The problems of fretting fatigue crack initiation in a press-fitted axle have not been completely solved even though up to-date fatigue design methods are employed. The objective of the present study is to clarify the effect of understress on fretting fatigue crack initiation behavior in the press-fitted axle. Most of the stress amplitude given to the axle in service is smaller than the fretting fatigue limit based on the stress to initiate cracks under a constant load $\sigma_{w f 1}$. Rotating bending fatigue tests were performed using a $40 \mathrm{~mm}$-diameter press-fitted axle assembly. Two-step variable stresses consisting of $\sigma_{w f 1}$ and half or one-third of $\sigma_{w f 1}$ were used in the experiment. Crack initiation life was defined as the number of cycles when a fretting fatigue crack, which is longer than $30 \mu \mathrm{m}$, was found using a metallurgical microscope. Fretting fatigue cracks were initiated even when the variable stress did not contain the stress above the fretting fatigue crack initiation limit. The crack initiation life varied from $4.0 \times 10^{7}$ to $1.2 \times 10^{8}$ depending on the stress frequency ratio $n_{L} / n_{H}$. The sum of the number of cycles of higher stress at crack initiation $N_{H}$ was much smaller than the number of cycles to initiate cracks estimated from the modified Miner's rule. The value of the modified Miner's damage ranged from 0.013 to 0.185 . To clarify the effect of variable amplitude on the fretting fatigue crack initiation, a comprehensive investigation related to relative slip, tangential force and fretting wear is necessary.
\end{abstract}

Key Words: Fretting Fatigue, Railway Axle, Variable Stress, Understress, Crack Initiation

\section{Introduction}

The objective of the present study is to clarify the effect of understress, which is defined as the stress below the fatigue limit based on the stress to initiate cracks under a constant loading $\sigma_{w f 1}$, on the fretting fatigue crack initiation of a press-fitted axle by considering the service loading condition. There are extensive studies on the fatigue strength of railway axles. However, the effect of variable amplitude stresses on the fretting fatigue is not fully understood $^{(1)}$, since most of these studies were carried out using a constant stress amplitude. In order to extend

* Received 29th November, 2002 (No. 02-4264)

** Department of Intelligent Machinery \& Systems, Kyushu University, 6-10-1 Hakozaki, Higashi-ku, Fukuoka 812-8581, Japan. E-mail: kubota@mech. kyushu-u.ac.jp

*** Graduate student, Kyushu University, 6-10-1 Hakozaki, Higashi-ku, Fukuoka 812-8581, Japan the axle inspection interval and to achieve an increased acceleration to the maximum speed in service of $350 \mathrm{~km} / \mathrm{h}$, a thorough investigation is requested in this area.

Axles are one of the most important components in railway vehicles with regard to safety, since a fail safe design is not available from the view point of fatigue strength. The critical part of the railway axle is the press-fitted part such as at the wheel seat where fretting fatigue cracks may initiate. Fretting fatigue damage is localized at the very near surface of the axle and the stresses of the axle given in service, which are below the allowable stress, produce a very slow growth rate of the fatigue cracks. Therefore, the fretting fatigue cracks at the press-fitted part are considered to be non-propagating cracks ${ }^{(1)}$. However, expensive regular maintenance and inspection are indispensable to ensure the safety regarding the fatigue failure of axles. The axles for the Shinkansen are removed from the wheels after $450000 \mathrm{~km}$, and a 
magnetic particle inspection is carried out. If there is a crack larger than $0.15 \mathrm{~mm}$ in depth, the axle will be scrapped $^{(2)}$. The total number of axles for inspection amounts to about 20000 each year ${ }^{(2)}$.

Since the start of the Shinkansen, various improvements related to materials, manufacturing processes, testing, design and maintenance have steadily been made. Consequently, no fretting fatigue cracks have been detected by the magnetic particle inspection for the past several years ${ }^{(3)}$. Therefore, a discussion to extend the inspection period is presently underway ${ }^{(4),(5)}$.

The bending stress of the axle is calculated by incorporating the accelerated gravity forces due to vibration of the body ${ }^{(6)}$. The accelerated forces increase as the velocity increases. To provide running stability at high speed, reduction of the mass under the spring, i.e., reduction of the wheelset weight is extremely effective. Although the stress on the axle increases as the speed increases, the weight of the axle should be reduced by making the diameter and the length of the axle smaller and using a hollow axle.

\section{Experimental Procedure}

\subsection{Variable stresses}

The variable stresses used in the experiment were based on the fact that most of the stress amplitude given to the axle in service is lower than the fretting fatigue limit based on the stress to initiate cracks under a constant load $\sigma_{w f 1}{ }^{(7)}$. Here, the crack initiation life was defined as the number of cycles when a fretting fatigue crack with a length longer than $30 \mu \mathrm{m}$ is found using a metallurgical microscope. The twostep multiple stress shown in Fig. 1 was used in the experiment. Stress amplitudes were chosen by referring to the stress distribution measured by the actual running test of the Shinkansen from Tokyo to Hakata covering about $1.000 \mathrm{~km}^{(8)}$.

The maximum stress amplitude of the actual axle produced in service was estimated to be $69 \mathrm{MPa}$. The value of $\sigma_{w f 1}$ of the actual axle, which was $64 \mathrm{MPa}^{(9)}$, was almost equal to the maximum stress. Therefore, the high-level stress amplitude $\sigma_{H}$ used in the experi-

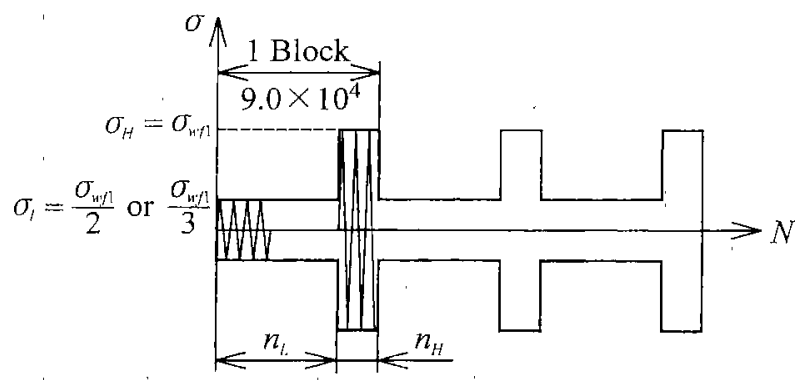

Fig. 1 Two-step multiple loading ment was determined so that it is the same as the $\sigma_{w f 1}$ of the specimen. The value of the $\sigma_{w f 1}$ for the $40-\mathrm{mm}$ diameter axle used in the present study was $118 \mathrm{MPa}$ as shown in Fig. $2^{(4)}$

The stress caused in the actual axle when the train runs in a straight line and relatively large corners whose curvature radius is over $8500 \mathrm{~m}$ was smaller than half of the $\sigma_{w f 1}$ of the actual axle. Also, the static stress caused by the wagon dead weight, which is the lowest stress on the actual axle, was one-third of the $\sigma_{w f 1}$. Therefore, half or one-third of the $\sigma_{w f 1}$ of the specimen was used as the low-level stress amplitude $\sigma_{L}$ in the experiment.

The parameter for the variable stresses is the stress frequency ratio $n_{L} / n_{H}$, which is defined as the ratio of the number of cycles of the high-level stress to that of the low-level one. The value of $n_{L} / n_{H}$ was set at 10, 40, 90 and 200 .

\subsection{Specimen and fatigue test}

The two-step multiple loading fretting fatigue test was performed using a $40 \mathrm{~mm}$ diameter pressfitted axle assembly as shown in Fig. 3. The assembly consists of an axle and a boss. The contact pressure between the axle and the boss is $70 \mathrm{MPa}$. Induction hardening was applied to the part of the axle which has a $40 \mathrm{~mm}$ diameter: The distribution of the axial residual stress below the surface is shown in Fig. 4. The surface compressive stress was maintained to a depth greater than about $1.5 \mathrm{~mm}$.

The axle was made of JIS S38C medium carbon steel. The boss was made of JIS SSW-1 high carbon

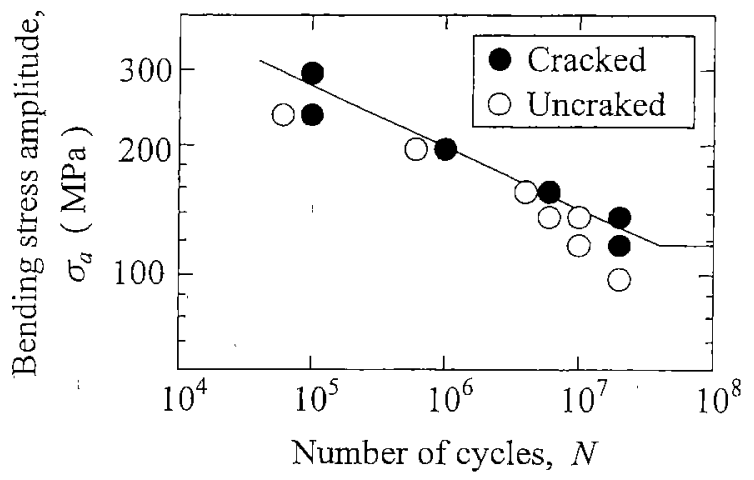

Fig. $2 S-N$ curve for crack initiation of the specimen under constant loading ${ }^{(4)}$

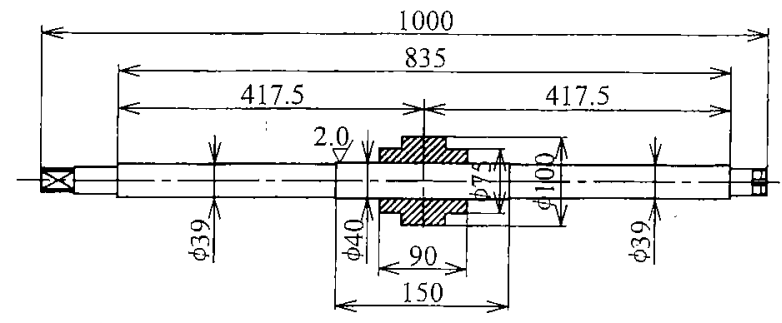

Fig. 3 Drawing of press-fitted axle assembly 
steel. The chemical compositions are shown in Table 1. The materials were the same as the Shinkansen axle and wheel. The mechanical properties of the materials are shown in Table 2.

Rotating bending fatigue test machines, whose load capacity is $4.4 \mathrm{kNm}$ and rotating speed is 1500 rpm, were used for the fretting fatigue tests. Both ends of the axle are supported by two ball bearings on the test machine so that the boss is midway between the bearings. The bending load is given to the boss by the servo-hydraulic loading equipment.

After certain loading cycles were produced on the axle, the boss was slightly slid to expose the fretted surface, and then observation of the surface with a metallurgical microscope was made to determine the crack initiation. When no crack was found, the boss was returned to the former place and the fatigue test was continued.

\section{Experimental Results}

\section{1 Fretting fatigue cracks}

Figure 5 shows the fretting fatigue cracks observed in the present study. There are many small

Table 1 Chemical compositions (wt \%)

\begin{tabular}{|c|c|c|c|c|c|}
\hline & $\mathrm{C}$ & $\mathrm{Si}$ & $\mathrm{Mn}$ & $\mathrm{P}$ & $\mathrm{S}$ \\
\hline S38C (Axle) & 0.38 & 0.28 & 0.76 & 0.009 & 0.008 \\
\hline SSW-1 (Boss) & 0.63 & 0.18 & 0.74 & 0.017 & 0.005 \\
\hline
\end{tabular}

Table 2 Mechanical properties

\begin{tabular}{|c|c|c|c|c|c|}
\hline & $\begin{array}{c}\sigma_{\mathrm{y}} \\
(\mathrm{MPa})\end{array}$ & $\begin{array}{c}\sigma_{\mathrm{B}} \\
(\mathrm{MPa})\end{array}$ & $\delta(\%)$ & $\varphi(\%)$ & $\mathrm{HV}$ \\
\hline $\mathrm{S} 38 \mathrm{C}$ & 433 & 689 & 29.0 & 60.5 & $620^{*}$ \\
\hline $\mathrm{SSW}-1$ & 361 & 779 & 19.5 & 34.7 & 227 \\
\hline
\end{tabular}

* Induction hardened surface

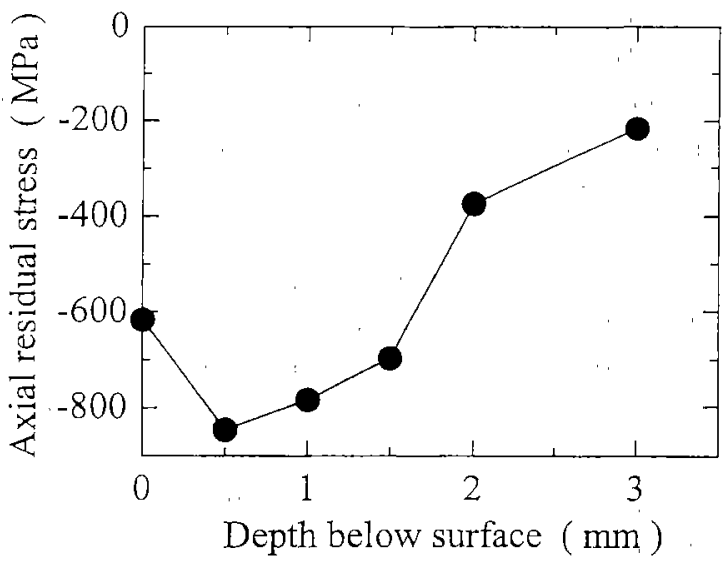

Fig. 4 Residual stress distribution below the surface cracks with many small pits. Below the surface, the cracks propagated at an angle to the surface. The crack length at the surface was from 65 to $134 \mu \mathrm{m}$. The aspect ratio of the cracks, which was from 0.3 to 0.4 , was equal to that obtained from the full-scale fatigue test ${ }^{(10)}$. As shown in Fig. 6 , the cracks were found at 3 or $4 \mathrm{~mm}$ inside from the contact edge where the fretting wear depth gradually decreases toward the center of the fitted part.

\section{2 Crack initiation life}

The results of the fretting fatigue tests are shown in Fig. 7. To put the result of the variable stresses onto the $S-N$ diagram, the variable stresses are converted into the equivalent stress of the modified Miner's rule $\sigma_{e q}$. The value of $\sigma_{e q}$ has no physical meaning. The cracks such as those shown in Fig. 5 were found under all stress conditions with different

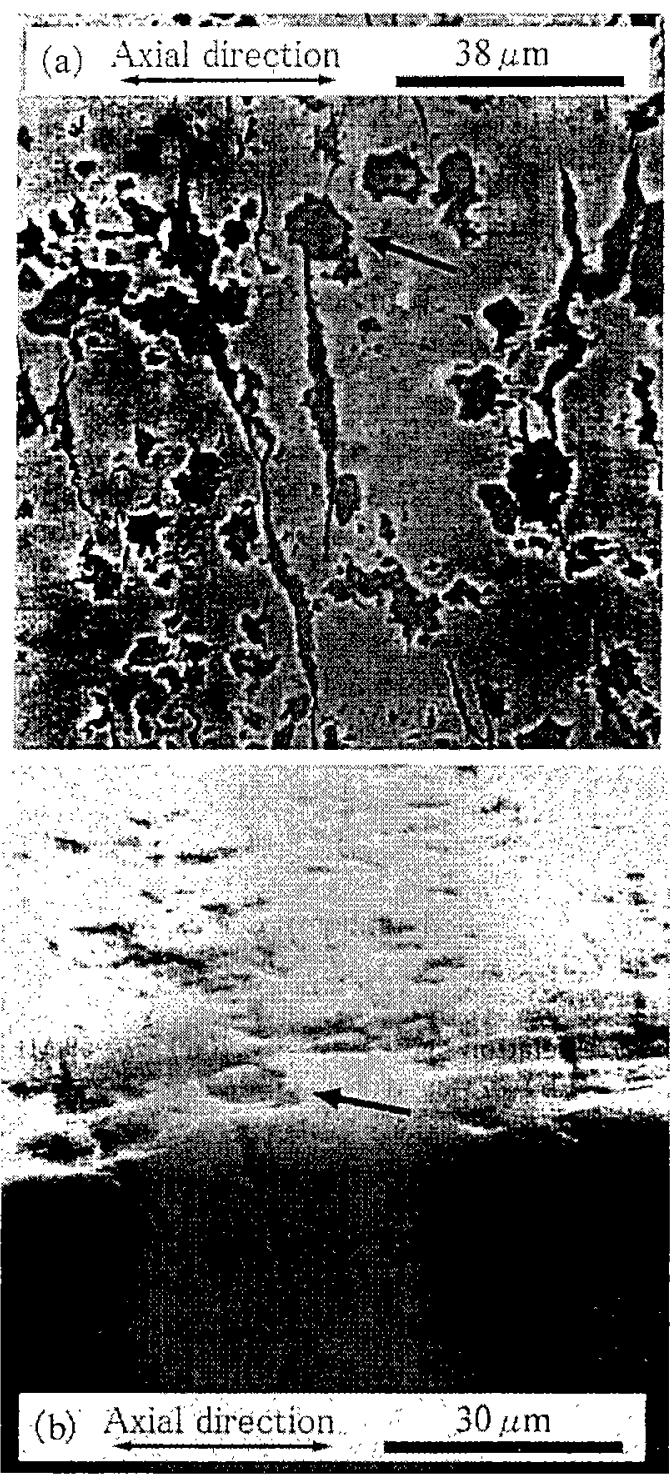

Fig. 5 Fretting fatigue cracks $\left(\sigma_{H}=118 \mathrm{MPa}, \sigma_{L}=59\right.$ $\mathrm{MPa}, n_{L} / n_{H}=40, N_{i}=8.03 \times 10^{7}$, (a) Fretted surface, (b) Axial section 


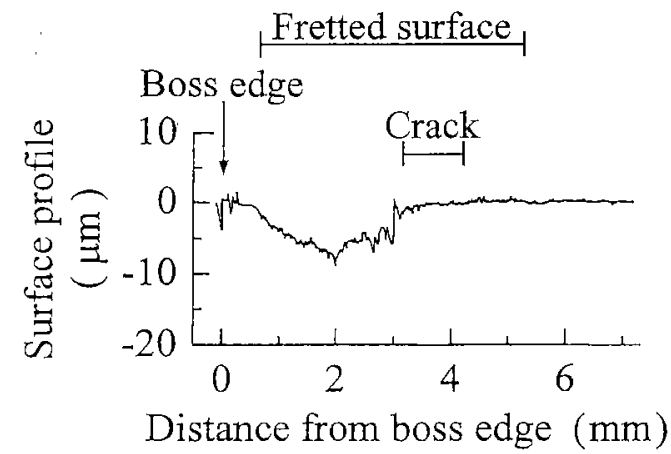

Fig. 6 Crack initiation site $\left(\sigma_{H}=118 \mathrm{MPa}, \sigma_{L}=59 \mathrm{MPa}\right.$, $\left.n_{L} / n_{H}=90, N_{i}=5.28 \times 10^{7}\right)$

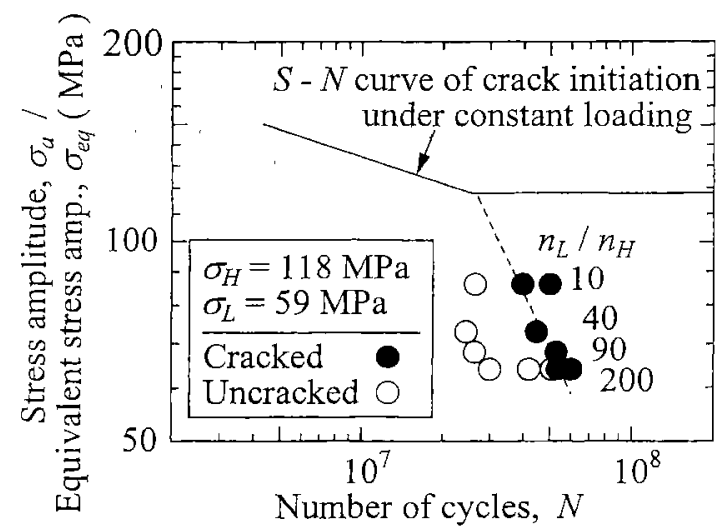

(a)

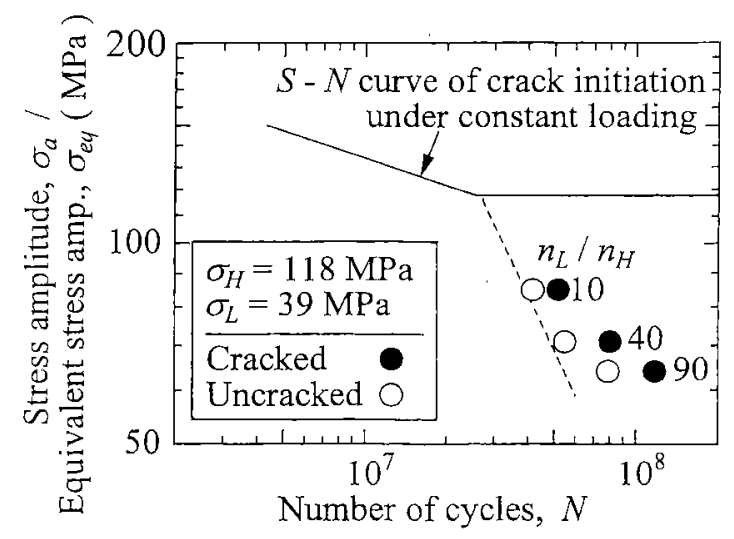

(b)

Fig. 7 Relation between $\sigma_{e q}-N_{i}$, (a ) $\sigma_{L}=59 \mathrm{MPa}$, (b) $\sigma_{L}=39 \mathrm{MPa}$

stress frequency ratios and low-level stress amplitudes. Fretting fatigue cracks were initiated even when the variable stress does not contain the stress above the fretting fatigue crack initiation limit in the constant loading test. The longest crack initiation life was more than $10^{8}$ cycles. It could be considered that these facts may be the reason why the fretting fatigue failure occurs after a very long period in service, in which the stress is below the fretting fatigue limit for a constant loading.

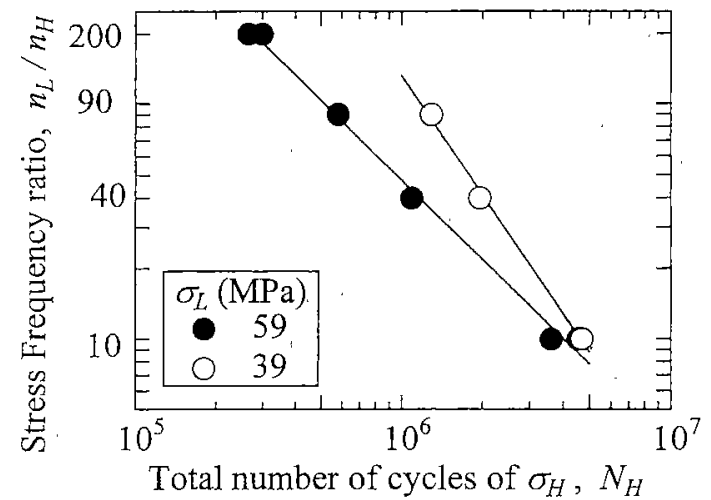

Fig. 8 Decrease in $N_{H}$ with increase in $n_{L} / n_{H}$

\section{Discussion}

\subsection{Effect of stress frequency ratio}

As shown in the previous figures, the crack initiation life increased with an increase in $n_{L} / n_{H}$. The reason for this is that the number of high-level stresses in one loading block $n_{H}$ decreases with an increase in $n_{L} / n_{H}$. However, the increase in the crack initiation life was not enough to make up for the decrease in the number of cycles of the high-level stress. Therefore, as:shown in Fig. 8, the sum of $n_{H}$ at crack initiation $N_{H}$ decreased with the increase in $n_{L} / n_{H}$. The low-level stress is unable to generate cracks by itself, although the number of cycles of the low-level stress increased with the increase in $n_{L} / n_{H}$. Therefore, it can be considered that the increase in $n_{L} / n_{H}$ has the effect of promoting fretting fatigue crack initiation. This shows that even if the frequency of the occurrence of the higher stress decreases by the improvement of the tracks, microcracks may still occur.

\section{2 Modified Miner's damage}

Figure 9 shows the modified Miner's damage $D$, which was calculated based on the $S-N$ curve shown in Fig. 2, as related to the stress frequency ratio. The value of $D$ is expressed by Eq. (1).

$$
D=\frac{N_{H}}{N_{H_{i}}}+\frac{N_{L}}{N_{L_{i}}}
$$

Here, $N_{H_{i}}$ and $N_{L_{i}}$ are the virtual crack initiation life obtained by the extension of the slope of the $S-N$ curve for a constant load below the fatigue limit and $N_{L}$ is the sum of $n_{L}$ at crack initiation. The value of $D$, which varied from 0.013 to 0.185 , was considerably smaller than 1.0. The value of $D$ agrees with the result for microcrack initiation of the actual axle ${ }^{(9)}$. The value of $D$ linearly decreased with the increase in $n_{L} / n_{H}$ on the $\log -\log$ graph. Figure 10 separately shows $N_{H}$ and $N_{L}$ on the $S-N$ diagram. The solid line shows the $S-N$ curve for crack initiation under constant loading. The ratio between $N_{L}$ and $N_{L i}$, which is 


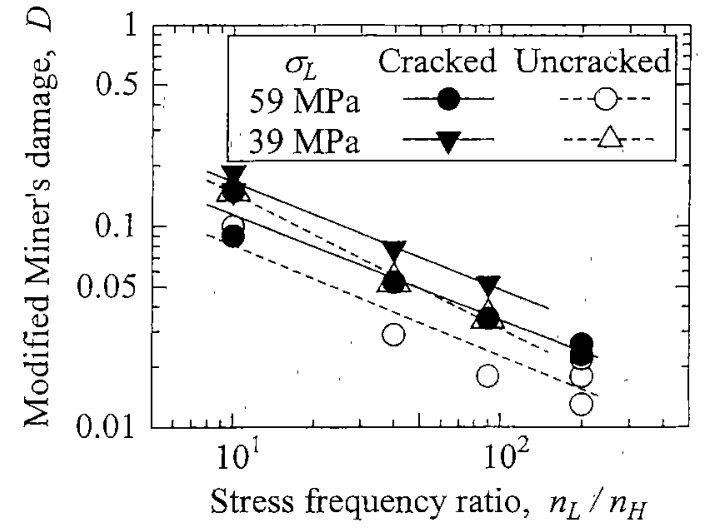

Fig. 9 Modified Miner's damage

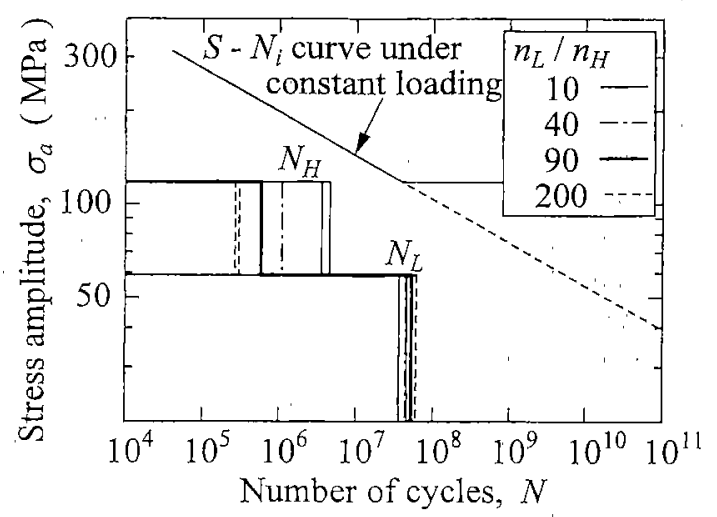

Fig, 10 Effect of $n_{L} / n_{H}$ on $N_{H}$ and $N_{L}\left(\sigma_{L}=59 \mathrm{MPa}\right)$

the second term in Eq. (1), was almost constant, since $N_{L i}$ is significantly larger than $N_{L}$. Therefore, the decrease in $D$ was dominated by the decrease in $N_{H}$.

\section{3 Mechanisms of crack initiation}

As mentioned before, no crack was found at the site where the most severe'fretting wear took place and the contact edge where there is a very high elastic stress concentration. The reason for this is that severe wear wears away the incipient fretting fatigue cracks $^{(11)}$ as shown in Fig. 11 (a). Also, the largest amplitude of the maximum shear stress, which may be related to the crack initiation, arises at the inner surface of the contact area when the relative slip is comparatively large ${ }^{(12)}$.

The initiation of the fretting fatigue cracks found at the inner surface of the contact area is concerned with the balance between the crack nucleation, fretting wear and the stress conditions. The fretted area of the fitted axle is not the entire surface where the boss is fitted but is only limited to the contact edge. As shown in Fig. 12, the fretted area extends or contracts depending on the stress amplitude. When the fretted area is changed, the crack initiation site moves and the distribution of the relative slip and tangential force between the contact surfaces, which have large effects on the stress distribution between the contact

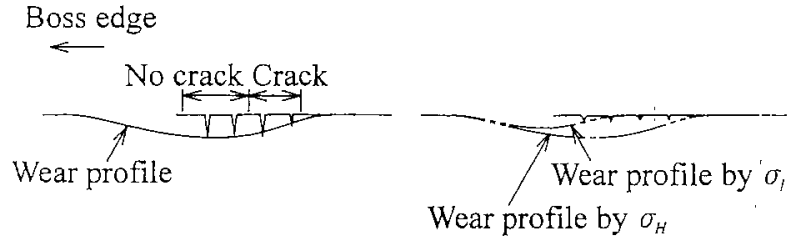

(a)

(b)

Fig. 11 Interaction between fretting wear and crack nucleation, (a) Constant loading, (b) Variable loading

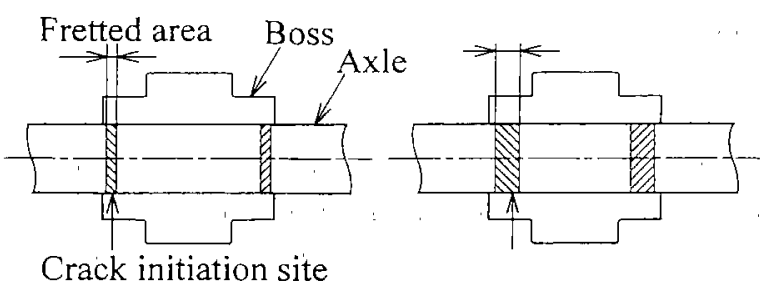

(a)

(b)

Fig. 12 Occurrence of fretting depending on stress amplitude, (a ) lower stress, (b) higher stress

surfaces, also changes. Therefore, the rivalry between crack nucleation and fretting wear under variable loadings is different from that of constant loading as shown in Fig. 11(b). Also, the stress condition surrounding the incipient cracks is different. Clarifying the effect of the tangential force and relative slip is very important for clarification of the mechanism of crack initiation under variable loading.

In the present study, the crack initiation is defined as the time in which a fretting fatigue crack with a length longer than $30 \mu \mathrm{m}$ is found. Therefore, very small cracks, which are invisible using an optical microscope, may exist when the constant loading fatigue test is carried out with the stress amplitude of $\sigma_{w f 1}$. The crack initiation life in the present study involves the crack propagation period in which a crack grows to a length of $30 \mu \mathrm{m}$. It is postulated that the crack propagation is influenced by the variable loading.

Murakami et al. ${ }^{(13)}$ clarified the effect of the stress amplitude to be lower than the fatigue limit on crack propagation. The variable loading fatigue test was carried out using a two-step stress which consists of two stress amplitudes such that the fatigue limit is sandwiched by them. Crack propagation during the variable loading test was significantly accelerated in comparison with that in the constant loading test under certain conditions. Further investigation is necessary to determine whether or not the crack propagation is accelerated by the variable loading when the crack length is below the identification limit using the optical microscope. 


\section{Conclusions}

The two-step multiple loading fretting fatigue test was performed using a $40 \mathrm{~mm}$ diameter pressfitted axle assembly to clarify the effect of variable stresses on the crack initiation in railway axles. The variable stresses were chosen based on the fact that most of the stress amplitude produced in the highspeed railway axle in service is smaller than the fretting fatigue limit for the microcrack initiation. The high-level stress was chosen as the fretting fatigue limit based on the stress to initiate cracks in the $40 \mathrm{~mm}$ axle. The low-level one was one-half or one-third of the high-level stress. Therefore, there was no stress higher than the crack initiation limit in the variable stresses. Crack initiation was defined as the time when a crack, which is longer than $30 \mu \mathrm{m}$, was found using a metallurgical microscope.

Fretting fatigue cracks were initiated even when the variable stress did not contain the stress above the fretting fatigue crack initiation limit obtained from the constant loading fatigue test. The longest crack initiation life was more than $10^{8}$ cycles. The sum of the high-level stress cycles at the crack initiation $N_{H}$ decreased with an increase in the ratio between the number of cycles of the low-level stress and that of the high-level one $n_{L} / n_{H}$. It can be considered that the increase in $n_{L} / n_{H}$ has the effect of promoting fretting fatigue crack initiation. The modified Miner's damage $D$ was considerably less than 1.0. The value of $D$ decreased with an increase in $n_{L} / n_{H}$, since $N_{H}$ decreased with an increase in $n_{L} / n_{H}$.

To clarify the mechanism of the crack initiation under variable loading, a comprehensive investigation related to the balance between the crack nucleation and fretting wear and the stress condition surrounding the incipient cracks is necessary.

\section{References}

(1) Hirakawa, K. and Kubota, M., On the Fatigue Design Method for High-Speed Railway Axles, Proc. Instn. Mech. Engers., Vol. 215, Part F, (2001), pp. 73-82.

(2) Ishizuka, H., Thirty Years of Axles Maintenance for Japanese Bullet Train - Shinkansen -, Proc. of 11th Int. Wheelset Congress, Australia, Vol. 2
(1995), pp. 43-46.

(3) Hirakawa, K., Toyama, K. and Kubota, M., The Analysis and Prevention of Failure in Railway Axles, Int. J. Fat., Vol. 20, No. 2 (1998), pp. 135144.

(4) Makino, T., Fretting Fatigue Properties on the Press-fitted Axles, Doctoral Thesis in Kyushu University, (in Japanese), (1999).

(5) Shimizu, M., Toda, N., Sakae, C., Jono, M. and Ishizuka, H., A Basic Study on Reliability of Axles for High-Speed Railway, Summary of Research Rerort for FY 2000, Vol. 1, Program for Promoting Fundamental Transport Technology Research, Corporation for Advanced Transport \& Technology (CATT), (in Japanese), (2002).

(6) Railway Rolling Stock-Design Methods for Strength of Axles-, E 4501. (in Japanese), (1995), Japanese Standards Association.

(7) Makino, T., Yamamoto, M. and Hirakawa, K., The Fretting Fatigue Crack Initiation Behavior at Press-Fitted Axle Assembly with Variable Stress Loading (Effect of Stress Cycle Ratio, Number of Load Levels and Axle Size), Proc. of 12th Int. Wheelset Congress, Qingdao, (1998), pp. 147-152.

(8) Hirakawa, K., Private Communication.

(9) Komatsu, H., Study on Improvement of Fatigue Strength in Press-Fitted Axle, Doctoral Thesis in Kyushu University, (in Japanese), (1975).

(10) Ishizuka, H., Akama, M., Hanaoka, T., Sato, Y., Komatsu, H. and Tezuka, K., Fracture Mechanics Evaluation of Fatigue Tests Using Shinkansen Vehicle Axles with Artificial Flaws Created on Their Wheelseats, Trans. Jpn. Soc. Mech. Eng., (in Japanese), Vol.60, No. 578 (1994), pp. 22002206.

(11) Nishioka, K: and Hirakawa, K., Fundamental Investigation of Fretting Fatigue, Part 5, Effect of Relative Slip Amplitude, Bulletin of JSME, Vol. 12, No. 52 (1969), pp. 692-697.

(12) Kubota, M., Tsutsui, K., Makino, T. and Hirakawa, K., The Effect of the Contact Conditions and Surface Treatments on the Fretting Fatigue Strength of Medium Carbon Steel, ASTM STP 1367, (2000), pp. 477-490.

(13) Murakami, Y. and Matsuda, K., Role of Small Cracks and Understress in Prediction of Fatigue Life under Two-Step Stress Loading, Trans. Jpn. Soc. Mater. Sci., Vol. 36, No. 409 (1987), pp. 10651070. 